\title{
Reply to the letter by Wong et al.
}

\section{Joanne Rimmer}

Department of Otolaryngology Head \& Neck Surgery, Monash Health, Department of Surgery, Monash University, Melbourne, Australia
Rhinology 57: 6, 479, 2019

https://doi.org/10.4193/Rhin19.269.1

*Received for publication:

August 26, 2019

Accepted: September 1, 2019

\section{Dear Editor,}

We welcome the comments relating to the recently published European Position Paper on Diagnostic Tools in Rhinology ${ }^{(1)}$. This document aimed to provide a comprehensive description of the diagnostic tools currently available to physicians, none of which are considered screening tests.

Screening, as defined by the World Health Organisation, is the presumptive identification of unrecognized disease in an apparently healthy, asymptomatic population by means of tests, examinations or other procedures that can be applied rapidly and easily to the target population (2). Patients seeking medical attention for a rhinological problem can be assumed to have at least one sinonasal symptom and are not therefore being scree- ned for an asymptomatic disease.

The tools described in the position paper may assist clinicians in diagnosis, planning treatment and monitoring response to that treatment. Whilst most are readily available in routine clinical practice, some remain more the realm of tertiary centres and research laboratories - for example, rhinomanometry and acoustic rhinometry. Computational fluid dynamics (CFD) is in development for the objective measurement of nasal obstruction, but currently remains almost exclusively in the research domain. We await the development of CFD technology that can be used in everyday clinical practice and hope to include a description of such tools in future updates.

\section{References}

1. Rimmer J, Hellings P, Lund V, Alobid I, Beale $T$, Dassi $C$ et al. European position paper on diagnostic tools in rhinology. Rhinology 2019 Supp 28:1-41.

2. https://www.who.int/cancer/prevention/diagnosis-screening/screening/en (accessed 26 August 2019)
Dr. Joanne Rimmer

Department of Otolaryngology

Head \& Neck Surgery

Monash Health

Department of Surgery

\section{Monash University}

Melbourne

Australia

E-mail: rimmer.joanne@gmail.com 